\title{
Decadal changes in extreme daily precipitation in Greece
}

\author{
P. T. Nastos ${ }^{1}$ and C. S. Zerefos ${ }^{1,2,3}$ \\ ${ }^{1}$ Laboratory of Climatology and Atmospheric Environment, Faculty of Geology and Geoenvironment, National and \\ Kapodistrian University of Athens, Greece \\ ${ }^{2}$ National Observatory of Athens, Greece \\ ${ }^{3}$ Academy of Athens, Greece
}

Received: 25 August 2007 - Revised: 17 December 2007 - Accepted: 25 January 2008 - Published: 9 April 2008

\begin{abstract}
The changes in daily precipitation totals in Greece, during the 45-year period (1957-2001) are examined. The precipitation datasets concern daily totals recorded at 21 surface meteorological stations of the Hellenic National Meteorological Service, which are uniformly distributed over the Greek region. First and foremost, the application of Factor Analysis resulted in grouping the meteorological stations with similar variation in time. The main sub groups represent the northern, southern, western, eastern and central regions of Greece with common precipitation characteristics. For representative stations of the extracted sub groups we estimated the trends and the time variability for the number of days (\%) exceeding $30 \mathrm{~mm}$ (equal to the $95 \%$ percentile of daily precipitation for eastern and western regions and equal to the $97.5 \%$ percentile for the rest of the country) and $50 \mathrm{~mm}$ which is the threshold for very extreme and rare events. Furthermore, the scale and shape parameters of the well fitted gamma distribution to the daily precipitation data with respect to the whole examined period and to the 10-year sub periods reveal the changes in the intensity of the precipitation.
\end{abstract}

\section{Introduction}

A great scientific interest with respect to extreme precipitation events and their economic, social and ecological implications has been aroused especially during the last decades (Karl et al., 1995; IPCC, 2001; Zhang et al., 2001). According to IPCC (2001), extreme precipitation is difficult to reproduce, especially for the intensities and patterns of heavy rainfall which are heavily affected by the local scale. For this reason, it is necessary to study heavy and extreme precipita-

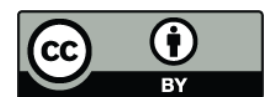

Correspondence to: P. T. Nastos (nastos@geol.uoa.gr) tion events by analyzing long time series of observed station data. Although regional differences are relatively high, annual precipitation trends in the 20th century, for a number of stations in Europe, exhibit a clear general positive trend for northern Europe, with the exception of Finland, and a negative for southern Europe and the Mediterranean (IPCC, 2001). Anagnostopoulou et al. (2006) studying the cyclones in the Mediterranean region, found that the Hadley Center Atmospheric General Circulation Model (HadAM3P) predicts a future decrease of the frequency of the severe cyclones $(<1000 \mathrm{hPa})$ at the SLP level, but the future cyclones will be more intense, especially at the $500 \mathrm{hPa}$ level.

Large changes in the wintertime atmospheric circulation have had a profound effect on regional distributions of surface temperature and precipitation. Anomalies in precipitation, including dry wintertime conditions over southern Europe and the Mediterranean and wetter-than-normal conditions over northern Europe and Scandinavia since 1980, are linked to the behaviour of North Atlantic Oscillation Index (NAOI) (Hurrell and van Loon, 1997). Besides, according to the results of Krichak and Alpert (2005), the precipitation decline over the Mediterranean region during the last decades of the past century can be explained by the positive trend in the East Atlantic Western Russia pattern, which was induced by the positive trend of the North Atlantic Oscillation. Regarding Greece, Feidas et al. (2007) found out that the observed downward trend in winter and annual precipitation in Greece is linked mainly to a rising trend in the hemispheric circulation modes of the NAOI, which are connected with the Mediterranean Oscillation Index. Moreover, lowfrequency fluctuations in the circulation over the Atlantic have been closely linked to the coherent large-scale precipitation anomalies that have persisted, particularly in winter, over Turkey since the early 1960s (Turkes and Erlat, 2003).

The precipitation variability and the distribution of precipitation frequency within the Mediterranean Sea and Greece have been carried out by many researchers (Repapis, 1986;

Published by Copernicus Publications on behalf of the European Geosciences Union. 


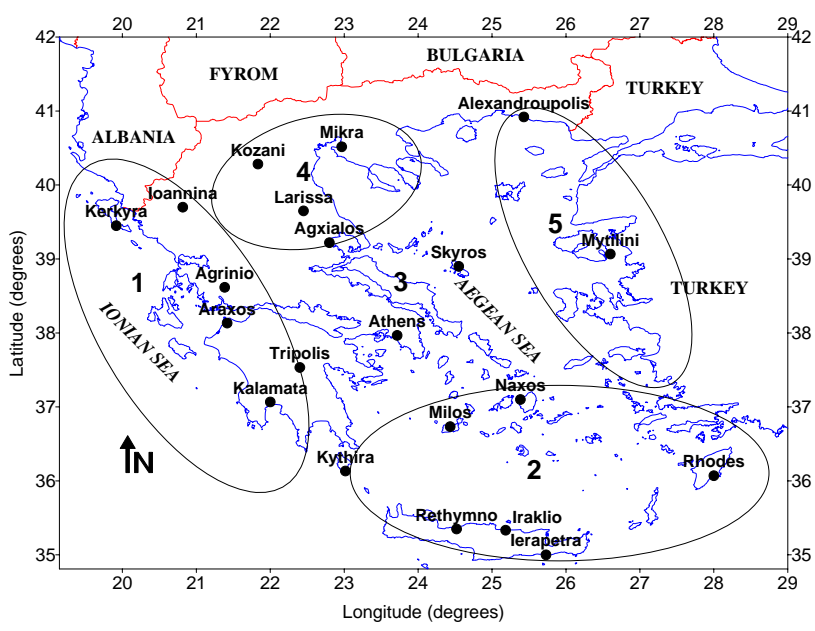

Fig. 1. Network of meteorological stations and the regions with common precipitation characteristics.

Nastos, 1993; Mantis et al., 1994; Metaxas et al., 1999; Brunetti et al., 2004; Nastos and Zerefos, 2007).

The objective of this study is to analyze the extreme daily precipitation time series recorded at 21 meteorological stations in Greece, for the period 1957-2001, by processing the time variability and the exceeding of the daily precipitation over various thresholds, which are indicators for the incidence of extreme rainfall events and by fitting the gamma distribution to the datasets per decade and for all the examined period, in order to reveal changes in the precipitation intensity.

\section{Data and analysis}

Daily precipitation totals recorded at 21 meteorological stations of the Hellenic National Meteorological Service for a 45-year period (1957-2001) were used for this study. The stations' network is satisfactorily distributed in Greek region (Fig. 1), representing well the precipitation of the country. The daily precipitation datasets give detailed report for the precipitation intensity and sufficient background for the evaluation of specific thresholds which provide more information about the trends and the time variability of extreme events.

First and foremost, the Factor Analysis (FA, S-mode) was applied to all available stations' datasets in order to reduce the number of variables and to detect structure in the relationships between variables that is to classify variables. Therefore each of the $\mathrm{p}$ initial variables (stations) $X_{1}, X_{2}, \ldots, \mathrm{X}_{p}$ can be expressed as a linear function of $\mathrm{m}(m<p)$ uncorrelated factors: $X_{i}=a_{i 1} F_{1}+a_{i 2} F_{2}+\ldots+\mathrm{a}_{i m} F_{m}$ where $F_{1}, F_{2}$, $\ldots, \mathrm{F}_{m}$ are the factors and $a_{i 1}, a_{i 2}, \ldots, \mathrm{a}_{i m}(i=1, \ldots p)$ are the factor loadings which express the correlation between the factors and the initial variables. The values of each factor are called factor scores and they are presented in standardized form, having zero mean and unit variance (Jolliffe, 1986). Another important point of the analysis is the rotation of the axes, which maximizes some factor loadings and minimizes some others and in that way a better separation among the initial variables is succeeded; for this reason Varimax rotation, which is generally accepted as the most accurate orthogonal rotation, was applied (Richman, 1986).

The second step was to examine, for representative stations within the regions extracted by FA, the temporal variability and trends of the time series of the number of precipitation days exceeding various thresholds such as $30 \mathrm{~mm}$, (equal to the $95 \%$ percentile of daily precipitation for eastern and western regions and equal to the $97.5 \%$ percentile for the rest of the country) and $50 \mathrm{~mm}$ which is the threshold for very extreme and rare events. Especially the threshold of $50 \mathrm{~mm}$ is considered representative of very extreme rainfalls, by many researchers (Karl et al., 1995; Brunetti et al., 2004). The time variability for these constructed time series is estimated using the wavelet analysis (Torrence and Compo, 1998).

Finally, in order to estimate the probability of extreme events, the gamma distribution is applied to the daily precipitation datasets for the whole studied period and for the 10 -year sub periods examining changes in the occurrence of the extreme events. The gamma distribution, which in addition is recommended by the World Meteorological Organization (Thom, 1971; Neyers, 1990), is the most appropriate for studies relative to precipitation distributions due to its moderately skewed profile (Thom, 1958; Wilks, 1995). Furthermore, the increase in the scale parameter $\beta$ (appeared in the formula for the probability density function) results in stretching out the probability density distribution and therefore can be used in the determination of the probability of extreme events.

\section{Results and discussion}

The number of main factors (regions) was extracted by the application of FA on the monthly values of precipitation for the 21 meteorological stations, because FA is performed only in normal distributed variables. Five main factors (regions) with common precipitation characteristics were extracted by the application of FA, explaining $77 \%$ of the total variance. These represent the northern, southern, western, eastern and central regions of Greece (Fig. 1). For each such region, a representative station is selected for the analyses followed: Ioannina for western (1), Iraklio for southern (2), Mikra for northern (3), Mytilini for eastern (4) and Athens (National Observatory of Athens) for central (5) region. The representative station for each region was selected mainly as the station within the region with the highest factor loading. Firstly, the annual number of precipitation days exceeding the specific thresholds such as $30 \mathrm{~mm}$ and $50 \mathrm{~mm}$ was estimated. In the process, these values were divided by the respective number of the wet days for each year, and thereafter the 

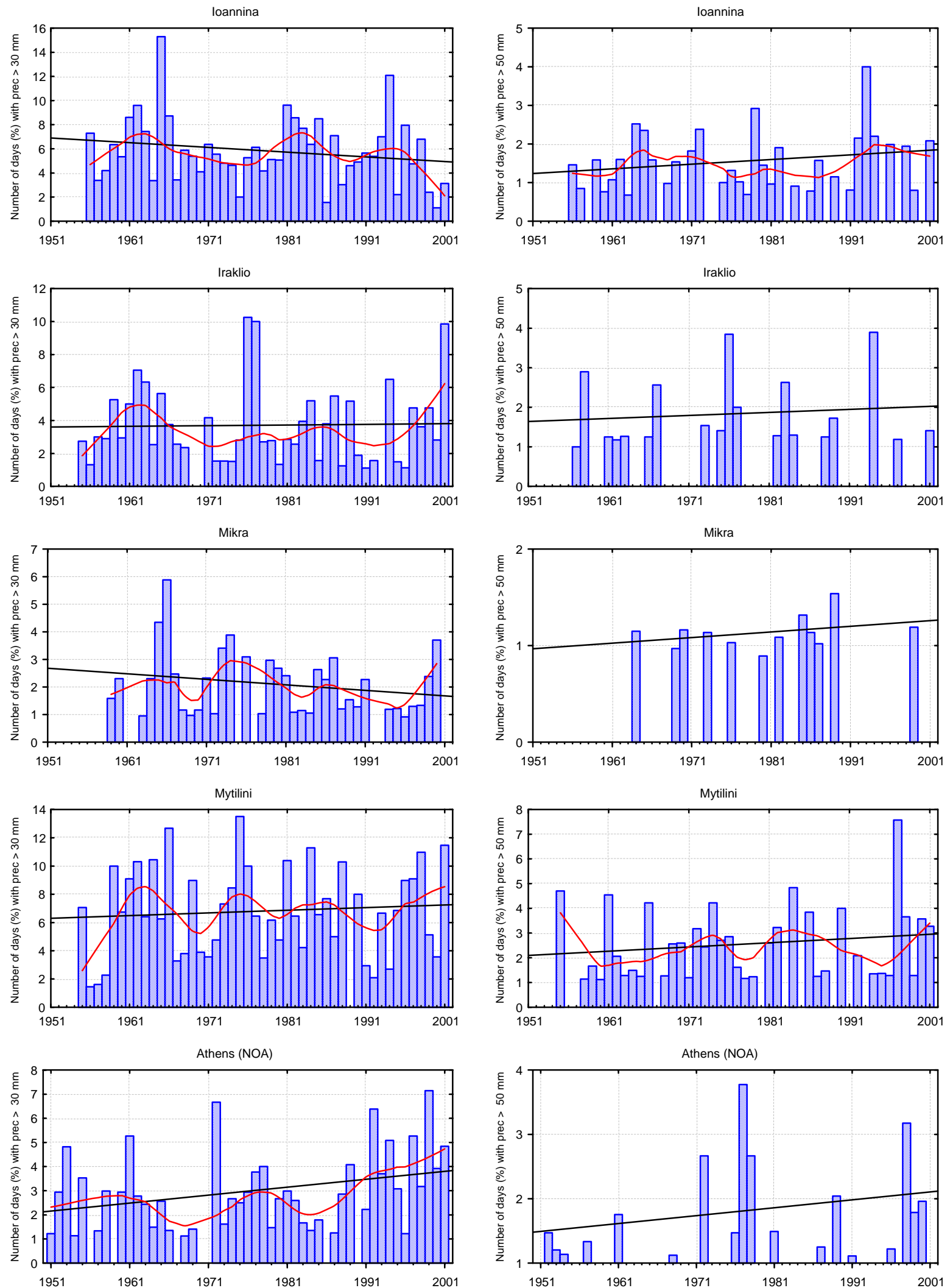

Fig. 2. Time series of the percentages (\%) of the annual number of days with precipitation greater than $30 \mathrm{~mm}$ and $50 \mathrm{~mm}$ (annual number of days exceeding specified thresholds divided by the number of wet days of the year), along with linear and loess fitting. 

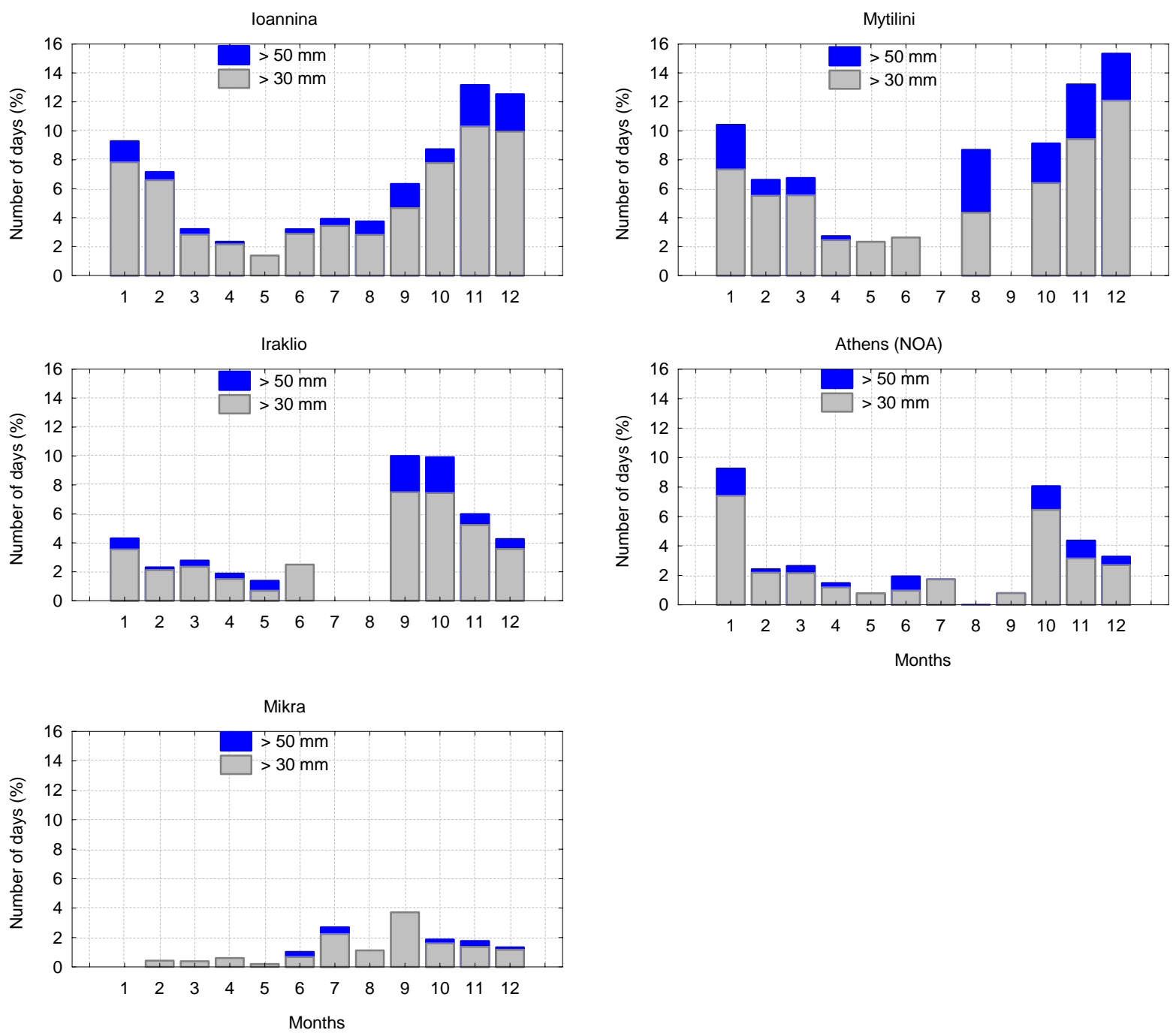

Fig. 3. Monthly distribution of the number of days (\%) with precipitation greater than $30 \mathrm{~mm}$ and $50 \mathrm{~mm}$ (monthly number of days exceeding the specified thresholds divided by the number of wet days of the respective month).

percentages $(\%)$ of the annual number of precipitation days exceeding these thresholds were calculated (Fig. 2). Regarding the threshold of $30 \mathrm{~mm}$, negative trends but statistically not significant $(0.05$ c.l.) appear in the western (Ioannina) and the northern (Mikra) regions, while rather stable trends appear in the southern (Iraklio) and the western (Mytilini) regions of Greece. Athens within the central region presents a statistically significant positive trend $(0.05$ c.l.), which has been pointed out in a previous study (Nastos and Zerefos, 2007). This is likely due to the urban heat island attributed to the extensive building of Athens after the Second World War and the rapid increase of the population and the number of vehicles mainly after 1970 (Philandras et al., 1999) combined with global warming during the recent decades.

On the one hand, warming is related to higher water content in the atmosphere (Douville et al., 2002; Trenberth et al., 2003) and this has been evident in many regions (Sun et al., 2000; Ross and Elliott, 2001) resulted in an increase in the probability of severe convective weather (Bornstein and Lin, 2000; Guo et al., 2006). On the other hand, the extreme and rare events represented by the threshold of $50 \mathrm{~mm}$ appear a slight positive trend which is not statistically significant all over the country. Groisman et al. (2005) found that changes in heavy precipitation frequencies are always higher than changes in precipitation totals and, in some regions, an increase in heavy and/or very heavy precipitation occurred while no change or even a decrease in precipitation totals was observed.

The monthly distributions of the percentages $(\%)$ of the number of days with precipitation greater than 30 and $50 \mathrm{~mm}$, for the representative stations from the regions extracted, are depicted in the stacked graphs of the Fig. 3. The extreme and 

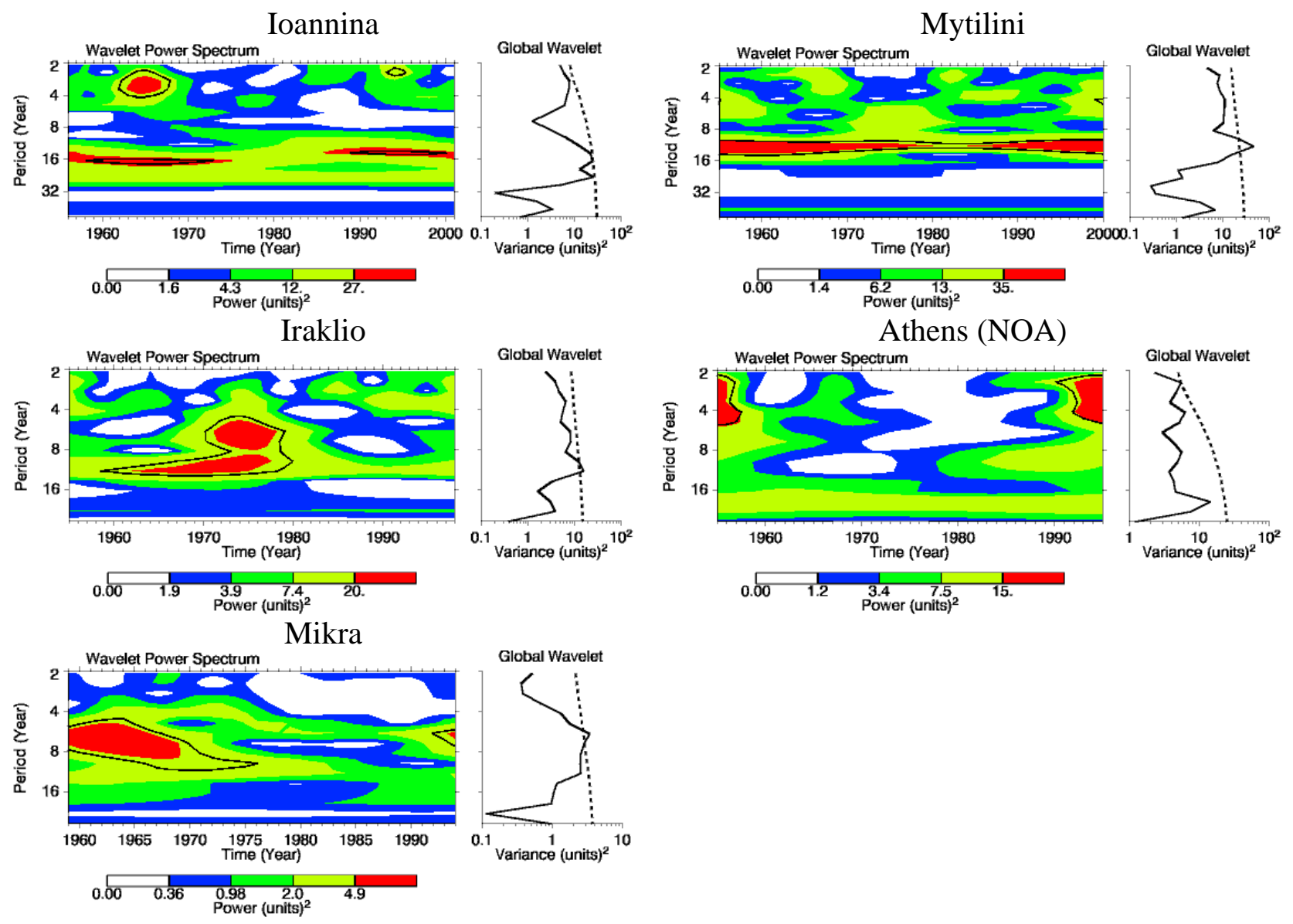

Fig. 4. The wavelet power spectrum (left graph) and the global wavelet power spectrum (right graph) for the time series of the annual number of days (\%) with precipitation greater than $30 \mathrm{~mm}$.

rare precipitation events appear mainly during winter months with respect to western and eastern regions and specifically the days (\%) with precipitation greater than $50 \mathrm{~mm}$ turn up more frequent within the eastern region (Mytilini) while are also more evident in August. Regarding the southern region, the extreme events appear their peaks during autumn months (September to October) while their occurrence is minimized in summer. In northern region, the precipitation extremes are diminished and are obvious especially in July and September, while in Athens the peaks appear in January and October.

In the process, wavelet analysis (Torrence and Compo, 1998) is used to identify variations in temporal cycles in the extreme precipitation events and furthermore to find relationships between these extremes and the dominant modes of the climate variability. Wavelet analysis was applied only in the time series of the annual number of days (\%) with precipitation greater than $30 \mathrm{~mm}$ and not in the time series with the threshold of $50 \mathrm{~mm}$, because these time series appear a lot of gaps and a small sample size, due to the rareness of these very extreme events. The analysis of climate extremes and their changes requires a very careful procedure. There is

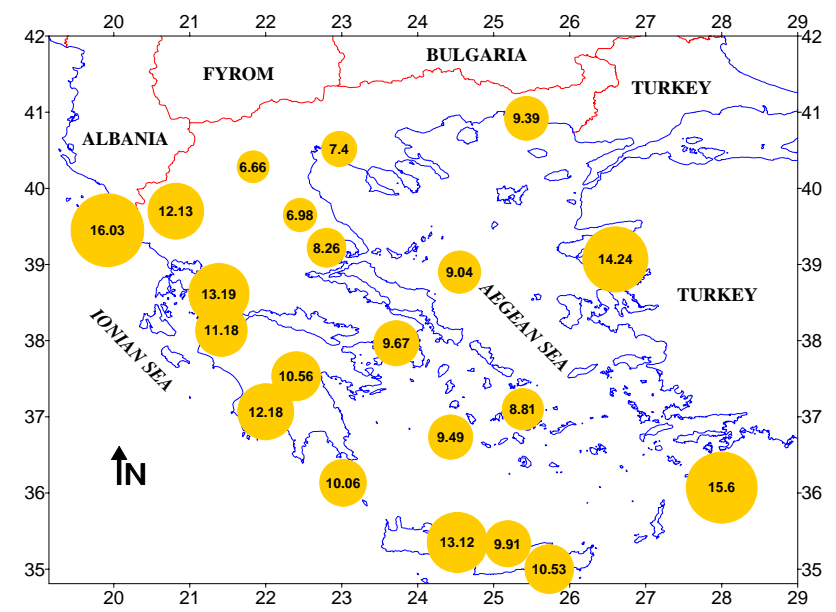

Fig. 5. Spatial distribution of the scale parameter of the gamma distribution fitted to daily precipitation totals. 
Table 1. Parameters of the gamma distribution fitted to daily precipitation data for the whole examined period (1957-2001).

\begin{tabular}{|c|c|c|c|c|c|c|c|c|c|c|c|}
\hline & Stations & ObservedMean & Observed Variance & Scale & Shape & & Stations & ObservedMean & ObservedVariance & Scale & Shape \\
\hline 1. & Kozani & 5.58 & 53.45 & 6.66 & 0.84 & 11. & Kythira & 7.35 & 106.15 & 10.06 & 0.73 \\
\hline 2. & Larissa & 5.16 & 64.12 & 6.98 & 0.74 & 12. & Ierapetra & 8.29 & 148.05 & 10.53 & 0.79 \\
\hline 3. & Mikra & 5.42 & 58.70 & 7.40 & 0.73 & 13. & Tripolis & 7.84 & 102.40 & 10.56 & 0.74 \\
\hline 4. & Agchialos & 5.97 & 85.29 & 8.26 & 0.72 & 14. & Araxos & 8.32 & 110.81 & 11.18 & 0.74 \\
\hline 5. & Naxos & 5.99 & 76.89 & 8.81 & 0.68 & 15. & Ioannina & 9.39 & 125.97 & 12.13 & 0.77 \\
\hline 6. & Skyros & 6.66 & 84.51 & 9.04 & 0.74 & 16. & Kalamata & 8.34 & 140.21 & 12.18 & 0.68 \\
\hline 7. & Alexndroupolis & 6.42 & 92.04 & 9.39 & 0.68 & 17. & Rethymno & 9.22 & 179.02 & 13.12 & 0.70 \\
\hline 8. & Milos & 7.02 & 95.49 & 9.49 & 0.74 & 18. & Agrinio & 9.71 & 160.51 & 13.19 & 0.74 \\
\hline 9. & Athens (NOA) & 6.23 & 94.93 & 9.67 & 0.64 & 19. & Mytilini & 9.57 & 179.97 & 14.24 & 0.67 \\
\hline \multirow[t]{2}{*}{10.} & Iraklio & 6.95 & 100.02 & 9.91 & 0.70 & 20. & Rhodes & 10.16 & 250.14 & 15.60 & 0.65 \\
\hline & & & & & & 21. & Kerkyra & 10.69 & 226.40 & 16.03 & 0.67 \\
\hline
\end{tabular}

Table 2. Parameters of the gamma distribution fitted to daily precipitation data of representative stations in the western and southeastern regions, for 10-year sub periods.

\begin{tabular}{lllll}
\hline Stations & ObservedMean & Observed Variance & Scale & Shape \\
\hline (Western region) Janina & & & & \\
$1961-1970$ & 10.26 & 129.86 & 12.08 & 0.84 \\
$1971-1980$ & 9.14 & 116.77 & 11.74 & 0.78 \\
$1981-1990$ & 8.92 & 119.49 & 11.93 & 0.75 \\
$1991-2000$ & 8.88 & 135.61 & 12.26 & 0.72 \\
(Western region) Kerkyra & & & & \\
$1961-1970$ & 10.67 & 228.43 & 16.47 & 0.65 \\
$1971-1980$ & 10.63 & 201.87 & 15.16 & 0.70 \\
$1981-1990$ & 10.20 & 195.40 & 14.77 & 0.69 \\
$1991-2000$ & 10.68 & 240.06 & 16.52 & 0.65 \\
(Southeastern region) Rhodes & & & & \\
$1961-1970$ & 9.51 & 183.32 & 14.39 & 0.66 \\
$1971-1980$ & 9.95 & 209.02 & 15.58 & 0.64 \\
$1981-1990$ & 9.92 & 274.22 & 15.52 & 0.64 \\
$1991-2000$ & 11.26 & 337.97 & 17.59 & 0.64 \\
\hline
\end{tabular}

large uncertainty in the estimate of extremes, simply because they represent infrequent events with small sample size.

The wavelet power spectrum and the global wavelet power spectrum for the time series of the annual number of days (\%) with precipitation greater than $30 \mathrm{~mm}$ are depicted in Fig. 4. The contour levels are chosen so that $75 \%, 50 \%, 25 \%$, and $5 \%$ of the wavelet power is above each level, respectively. Black contour is the 5\% significance level, using a red-noise (autoregressive lag1) background spectrum. The dashed line is the significance level for the global wavelet spectrum, assuming the same significance level and background spectrum as in left graph. Wavelet analysis shows that decadal cycles (10 to 16 years), statistically significant $(0.05$ c.l.), dominate in the western and eastern regions, concerning the whole examined period. Moreover, 2-10 year periods are exhibited all over the country with less or more significance with respect to time.
The negative correlation between the number of days with precipitation greater than $30 \mathrm{~mm}$ and the North Atlantic Oscillation Index for December, January, February and March seems to be small $(\sim-0.2)$ and not statistically significant (at 0.05 c.l).

The probability of the extreme events is well determined by the scale and shape parameters of the fitted gamma distribution. The results show that the shape parameter of the precipitation gamma distributions remains rather stable in this period of study, independent of the total precipitation, while the scale parameter, which characterizes the scale of the intensity of the daily precipitation (the higher the scale parameter is, the higher the intensity is), is most variable (Fig. 5). High figures of the scale parameter appear in the western, eastern and southeastern Greece, while low ones appear mainly in the central continental Greece. Table 1 presents the parameters of the fitted gamma distribution along with the 
observed mean and variance for each station included in the analysis. The fitted gamma distributions to the precipitation datasets within 10-year sub periods indicate that increased scale parameter and observed variance appear for the western and southeastern regions (Table 2), especially during the last decade 1991-2000. The scale parameter and the observed variance are rather constant or of low variability for the rest stations of the country (not shown for brevity's sake).

\section{Conclusions}

The analysis of the extreme daily precipitation totals in Greece demonstrates the existence of positive trends, not statistically significant $(0.05$ c.l.), observed in daily precipitation totals exceeding 30 and $50 \mathrm{~mm}$ at the eastern and southeastern regions of the country. The application of the wavelet analysis to the time series of the number of days exceeding the above thresholds resulted in significant quasi biennial and quasi decadal periods. The extreme precipitation events appear during winter months in the western and eastern regions, and mainly during autumn in the rest of the country. Moreover, the fitted gamma distributions to the daily precipitation totals with respect to the 45-year period (1957-2001) reveal that high figures of the scale parameter appear in the western, eastern and southeastern Greece, while low ones appear mainly in the central continental Greece. Regarding the 10 -year sub periods, we found that increased observed variance and scale parameter are appeared in the western and southern-eastern regions, especially during the last decade 1991-2000, indicating the incidence of extreme daily precipitation.

Edited by: S. C. Michaelides

Reviewed by: two anonymous referees

\section{References}

Anagnostopoulou, C., Tolika, K., Flocas, H., and Maheras, P.: Cyclones in the Mediterranean region: Present and future climate scenarios derived from a general circulation model (HadAM3P), Adv. Geosci., 7, 9-14, 2006, http://www.adv-geosci.net/7/9/2006/.

Bornstein, R. and Lin, Q.: Urban heat islands and summertime convective thunderstorms in Atlanta: three cases studies, Atmos Environ, 34, 507-516, 2000.

Brunetti, M., Maugeri, M., Monti, F., and Nanni, T.: Changes in daily precipitation frequency and distribution in Italy over the last 120 years, J. Geophys. Res., 109, D05102, doi:10.1029/2003JD004296, 2004.

Douville, H., Chauvin, F., Planton, S., Royer, J. F., Salas-Melia, D., and Tyteca, S.: Sensitivity of the hydrological cycle to increasing amounts of greenhouse gases and aerosols, Clim. Dyn. 20, 4568, 2002.

Feidas, H., Noulopoulou, C., Makrogiannis, T., and Bora-Senta, E.: Trend analysis of precipitation time series in Greece and their relationship with circulation using surface and satellite data: 19552001, Theor. Appl. Climatol., 87, 155-177, 2007.
Groisman, P. Y., Knight, R. W., Easterling, D. R., Karl, T. R., and Hegerl, G. C.: Trends in intense precipitation in the climate record, J. Climate., 18(9), 1326-1350, 2005.

Guo, X., Fu, D., and Wang, J.: Mesoscale convective precipitation system modifiedd by urbanization in Beijing City, Atmos. Res., 82, 112-126, 2006.

Hurrell, J. W. and Van Loon, H.: Decadal variations in climate associated with the North Atlantic oscillation, Climatic Change, 36, 301-326, 1997.

IPCC: Climate Change 2001, The Scientific Basis, Contribution of Working Group 1 to the Third IPCC Scientific Assessment, Chapter 8, Model Evaluation, 2001.

Jolliffe, I. T.: Principal Component Analysis, Springer-Verlag, New York, 1986.

Karl, T. R., Knight, R. W., and Plummer, N.: Trends in highfrequency climate variability in the twentieth century, Nature, 377, 217-220, 1995.

Krichak, S. O. and Alpert, P.: Signatures of the NAO in the tmospheric circulation during wet winter months over the Mediterranean region. Theor. Appl. Climatol., 82, 27-39, 2005.

Mantis, H. T., Repapis, C. C., Philandras, C. M., Paliatsos, A. G., and Amanatidis, G. T.: The spatial and temporal structure of the precipitation climate the Eastern Mediterranean; Background for a study of Climate Change, EUR 17458 - Eastern Europe and Global Change, Kassandra, Halkidiki, Greece, 3-10 ctober 1994, 125-131, edited by: Ghazi, A., Mathy, P., and Zerefos, C., 1994.

Metaxas, D. A., Philandras, C. M., Nastos, P. T., and Repapis, C. C.: Variability of precipitation pattern in Greece during the year, Fresen. Environ. Bull., 8, 1-6, 1999.

Nastos, P. T.: Changements de la pluviosite en region Hellenique pendant la periode 1858-1992, Proceedings of the 6th Colloque International de Climatologie, 22-25 Septembre 1993, Thessaloniki, Grece, Vol. 6, 183-190, 1993.

Nastos, P. T. and Zerefos, C. S.: On extreme daily precipitation totals at Athens, Greece, Adv. Geosci., 10, 59-66, 2007, http://www.adv-geosci.net/10/59/2007/.

Neyers, S.: On the statistical analysis of meteorological observations, WMO Techn Note No. 143, 1990.

Philandras, C. M., Metaxas, D. A., and Nastos, P. T.: Climate variability and urbanization in Athens, Theor. Appl. Climatol., 63(12), 65-72, 1999.

Repapis, C. C.: Temporal fluctuations of precipitation in Greece. Rivista di Meteor Aeron, XLVI, 1-2, 19-25, 1986.

Richman, M. B.: Rotation of principal components J. Climatol., 6, 293-335, 1986.

Ross, R. J. and Elliott, W. P.: Radiosonde-based Northern Hemisphere tropospheric water vapour trends, J. Climate., 14, 16021612, 2001.

Sun, B., Groisman, P. Y., Bradley, R. S., and Keiming, F. T.: Temporal Changes in the Observed Relationship between Cloud Cover and Surface Air Temperature, J. Climate., 13, 4341-4357, 2000.

Thom, H. C. S.: A note on the gamma distribution, Mon. Weather Rev., 86, 117-122, 1958.

Thom, H. C. S.: Some methods of climatological analysis, WMO Techn Note No. 81, 1971.

Torrence, C. and Compo, G. P.: A Practical Guide to Wavelet Analysis, Bull. Amer. Meteor. Soc., 79, 61-78, 1998.

Trenberth, K. E., Dai, A., Rasmussen, R. M., and Parsons, D. B.: The changing character of precipitation, Bull. Amer. Meteorol. 
Soc., 84, 1205-1217, 2003.

Turkes, M.and Erlat, E.: Precipitation changes and variability in Turkey linked to the North Atlantic Oscillation during the period 1930-2000, Int. J. Climatol., 23, 1771-1796, 2005.

Wilks, D. S.: Statistical Methods in the Atmospheric Sciences, Academic Press: San Diego, CA, 1995.
Zhang, X., Hogg, W. D., and Mekis, E.: Spatial and temporal characteristics of heavy precipitation events in Canada, J. Climate., 14, 1923-1936, 2001. 